Buletin Ilmiah Math. Stat. dan Terapannya (Bimaster)

Volume 08, No. 4 (2019), hal 927 - 932.

\title{
INDEKS PENCEMARAN AIR DI KAWASAN PERMUKIMAN KOTA PONTIANAK: INDIKATOR FISIK DAN KIMIA
}

\author{
Puteri Ratna Dewi, Dadan Kusnandar, Naomi Nessyana Debataraja \\ INTISARI
}

\begin{abstract}
Air merupakan elemen yang sangat penting bagi manusia, salah satunya untuk keperluan higiene sanitasi. Penentuan indeks pencemaran air yang digunakan untuk keperluan higiene sanitasi berdasarkan Keputusan Menteri Lingkungan Hidup Nomor 115 Tahun 2003. Data yang digunakan adalah data primer yang terdiri dari 42 sampel air yang diambil di Kota Pontianak. Terdapat dua indikator yang digunakan antara lain fisik dan kimia. Indikator fisik yang digunakan pada penelitian ini adalah kekeruhan, warna, dan Total Dissolved Solid (TDS). Indikator kimia yang digunakan pada penelitian ini adalah pH, besi, fluorida, kesadahan, nitrat, nitrit, dan deterjen. Indeks pencemaran indikator fisik terdiri dari tiga kelas yaitu, 8 titik lokasi memenuhi baku mutu, 24 titik lokasi tercemar ringan, dan 10 titik lokasi tercemar sedang. Indeks pencemaran indikator kimia terdiri dari dua kelas yaitu, 12 titik lokasi memenuhi baku mutu dan 30 titik lokasi tercemar ringan.
\end{abstract}

Kata Kunci: pencemaran air, indeks pencemaran. sebaran indeks pencemaran

\section{PENDAHULUAN}

Air adalah salah satu elemen yang sangat berfungsi dan berperan bagi kehidupan makhluk hidup di bumi. Manusia harus selalu melestarikan dan menjaga kelestarian air. Salah satu kebutuhan pokok manusia dengan segala macam kegiatannya yaitu air untuk keperluan higiene sanitasi. Air untuk keperluan higiene sanitasi digunakan untuk mandi, sikat gigi, mencuci bahan pangan, peralatan makan, dan pakaian. Semakin meningkatnya pembangunan, semakin meningkat pula pencemaran pada perairan. Oleh sebab itu, untuk mencegah pencemaran dibutuhkan upaya pengendalian pencemaran lingkungan dengan menetapkan baku mutu kesehatan lingkungan.

Standar baku mutu kesehatan lingkungan dan persyaratan kesehatan air untuk keperluan higiene sanitasi diatur berdasarkan Peraturan Menteri Kesehatan Republik Indonesia Nomor 32 Tahun 2017 [1]. Terdapat dua indikator yang digunakan antara lain fisik dan kimia. Indikator fisik yang digunakan pada penelitian ini adalah kekeruhan, warna, dan Total Dissolved Solid (TDS). Indikator kimia yang digunakan pada penelitian ini adalah $\mathrm{pH}$, besi, fluorida, kesadahan, nitrat, nitrit, dan deterjen.

Tujuan penelitian adalah menentukan indeks pencemaran (IP) indikator fisik dan kimia di Kota Pontianak. Data yang digunakan adalah data primer yang terdiri dari 42 sampel yang diambil di Kota Pontianak. Sampel diambil menggunakan metode stratified random sampling.

\section{METODE PENELITIAN}

Penelitian menggunakan data yang bertempat di Kota Pontianak, Kalimantan Barat. Sampel diambil menggunakan metode stratified random sampling [2]. Terpilihlah 42 titik lokasi yang digunakan sebagai sampel melalui metode ini. Setelah lokasi terpilih, sampel air diambil kemudian diolah untuk mendapatkan hasil kandungan air dengan bantuan laboran.

Indeks yang berkaitan dengan senyawa pencemar yang bermakna untuk suatu peruntukan dinyatakan sebagai indeks pencemaran. Indeks pencemaran digunakan untuk menentukan tingkat pencemaran relatif. Indeks ini memiliki konsep yang berlainan dengan indeks kualitas air. Indeks pencemaran (PI) ditentukan untuk suatu peruntukan, kemudian dapat dikembangkan untuk beberapa peruntukan bagi seluruh bagian badan air atau sebagian dari suatu sungai [3]. 
Pengelolaan kualitas air atas dasar indeks pencemaran (PI) dapat memberi masukan pada pengambil keputusan. Pengambil keputusan dapat menilai kualitas badan air untuk suatu peruntukan serta melakukan tindakan untuk memperbaiki kualitas jika terjadi penurunan kualitas akibat kehadiran senyawa pencemar. Jika $C_{i j}$ menyatakan nilai hasil penelitian pada variabel ke- $i$ lokasi ke-j dan $L_{i j}$ menyatakan nilai baku mutu pada variabel ke- $i$ lokasi ke- $j$, maka indeks pencemaran pada lokasi ke- $j$ yang merupakan fungsi dari $C_{i j} / L_{i j}$ adalah $P I_{j}[3]$.

$$
P I_{j}=\sqrt{\frac{M_{j}^{2}+R_{j}^{2}}{2}}
$$

Keterangan:

$$
\begin{aligned}
& P I_{j}=\text { indeks pencemaran pada lokasi ke- } j \\
& R_{j}=\text { nilai rata-rata rasio } C_{i j} / L_{i j} \text { pada lokasi ke- } j \\
& M_{j}=\text { nilai maksimum rasio } C_{i j} / L_{i j} \text { pada lokasi ke-j }
\end{aligned}
$$

Metode ini dapat langsung menghubungkan tingkat ketercemaran dengan dapat atau tidaknya sungai dipakai untuk penggunaan tertentu dan dengan nilai parameter-parameter tertentu. Tabel 1 merupakan tabel kriteria indeks pencemaran.

Tabel 1 Kriteria Indeks Pencemaran

\begin{tabular}{ll}
\hline \multicolumn{1}{c}{ Kelas Indeks Pencemaran } & \multicolumn{1}{c}{ Keterangan } \\
\hline $0 \leq P I \leq 1,0$ & Memenuhi baku mutu \\
$1,0<P I \leq 5,0$ & Tercemar ringan \\
$5,0<P I \leq 10$ & Tercemar sedang \\
$P I>10$ & Tercemar berat \\
\hline
\end{tabular}

Sumber: Keputusan Menteri Negara Lingkungan Hidup Nomor 115 Tahun 2003

Harga $P I_{j}$ ini dapat ditentukan dengan cara:

1. Perhitungan harga $C_{i j} / L_{i j}$ untuk tiap variabel pada setiap lokasi pengambilan sampel.

2. Jika nilai baku $L_{i j}$ memiliki rentang

a. Untuk $C_{i j} \leq L_{i j}$ rata-rata

$$
\left(C_{i j} / L_{i j}\right)_{\text {baru }}=\frac{\left[C_{i j}-\left(L_{i j}\right)_{\text {rata-rata }}\right]}{\left\{\left(L_{i j}\right)_{\text {minimum }}-\left(L_{i j}\right)_{\text {rata-rata }}\right\}}
$$

b. Untuk $C_{i j}>L_{i j}$ rata-rata

$$
\left(C_{i j} / L_{i j}\right)_{\text {baru }}=\frac{\left[C_{i j}-\left(L_{i j}\right)_{\text {rata-rata }}\right]}{\left\{\left(L_{i j}\right)_{\text {maksimum }}-\left(L_{i j}\right)_{\text {rata-rata }}\right\}}
$$

3. Nilai $\left(C_{i j} / L_{i j}\right)$ digunakan sebagai hasil pengukuran apabila nilainya lebih kecil dari 1 dan penggunaan nilai $\left(C_{i j} / L_{i j}\right)$ baru apabila nilai $\left(C_{i j} / L_{i j}\right)$ hasil pengukuran lebih besar dari 1 . Nilai $\left(C_{i j} / L_{i j}\right)$ baru $=1,0+P \cdot \log \left(C_{i j} / L_{i j}\right)$ hasil pengukuran, $P$ adalah konstanta dan nilainya ditentukan dengan bebas (biasanya digunakan 5 ).

4. Penentuan nilai rata-rata dan nilai maksimum dari keseluruhan $C_{i j} / L_{i j}$.

5. Penentuan harga $P I_{j}$ dalam persamaan (1). 


\section{HASIL DAN PEMBAHASAN}

Standar baku mutu air yang digunakan adalah standar baku mutu kesehatan lingkungan dan persyaratan kesehatan air untuk keperluan higiene sanitasi, yang diatur dalam Peraturan Menteri Kesehatan Republik Indonesia Nomor 32 Tahun 2017 [1]. Tabel 2 adalah perhitungan nilai indeks pencemaran untuk indikator fisik.

Tabel 2 Nilai Indeks Pencemaran Indikator Fisik Sampel Pertama

\begin{tabular}{lcccc}
\hline Variabel & $C_{i j}$ & $L_{i j}$ & $\left(C_{i j} / L_{i j}\right)$ & $\left(C_{i j} / L_{i j}\right)$ baru \\
\hline Kekeruhan & 55,1 & 25 & 2,204 & 2,71606 \\
Warna & 785 & 50 & 15,7 & 6,9795 \\
TDS & 17,2 & 1000 & 0,0172 & 0,0172 \\
\hline$R_{j}{ }^{2}$ & & & & 10,4819593 \\
$M_{j}{ }^{2}$ & & & & 48,7134 \\
$P I_{j}$ & & & & 5,440375 \\
\hline
\end{tabular}

Pada Tabel 2 didapat hasil indeks pencemaran sebesar 5,440375 menurut tabel kriteria indeks pencemaran sampel pertama termasuk dalam kategori tercemar sedang. Hasil perhitungan seluruh sampel indikator fisik dapat dilihat pada Tabel 3 di bawah ini.

Tabel 3 Nilai Indeks Pencemaran Indikator Fisik

\begin{tabular}{cccccc}
\hline Sampel & $P_{j}$ & $\begin{array}{c}\text { Kriteria Indeks } \\
\text { Pencemaran }\end{array}$ & Sampel & $P I_{j}$ & $\begin{array}{c}\text { Kriteria Indeks } \\
\text { Pencemaran }\end{array}$ \\
\hline 1 & 5,440375 & Tercemar sedang & 22 & 4,463715 & Tercemar ringan \\
2 & 5,41935 & Tercemar sedang & 23 & 4,255671 & Tercemar ringan \\
3 & 5,825755 & Tercemar sedang & 24 & 4,961251 & Tercemar ringan \\
4 & 5,412943 & Tercemar sedang & 25 & 4,466458 & Tercemar ringan \\
5 & 5,509195 & Tercemar sedang & 26 & 0,788546 & Memenuhi Baku Mutu \\
6 & 4,484888 & Tercemar ringan & 27 & 4,999726 & Tercemar ringan \\
7 & 5,407533 & Tercemar sedang & 28 & 2,129691 & Tercemar ringan \\
8 & 5,630898 & Tercemar sedang & 29 & 4,917998 & Tercemar ringan \\
9 & 4,839126 & Tercemar ringan & 30 & 5,1099 & Tercemar sedang \\
10 & 0,683873 & Memenuhi Baku Mutu & 31 & 5,228082 & Tercemar sedang \\
11 & 2,763823 & Tercemar ringan & 32 & 2,800144 & Tercemar ringan \\
12 & 2,82216 & Tercemar ringan & 33 & 0,516578 & Memenuhi Baku Mutu \\
13 & 0,738324 & Memenuhi Baku Mutu & 34 & 1,772955 & Tercemar ringan \\
14 & 5,405725 & Tercemar sedang & 35 & 2,788535 & Tercemar ringan \\
15 & 1,410339 & Tercemar ringan & 36 & 1,84262 & Tercemar ringan \\
16 & 0,946004 & Memenuhi Baku Mutu & 37 & 1,709521 & Tercemar ringan \\
17 & 1,441701 & Tercemar ringan & 38 & 3,230933 & Tercemar ringan \\
18 & 0,528815 & Memenuhi Baku Mutu & 39 & 3,677802 & Tercemar ringan \\
19 & 1,872464 & Tercemar ringan & 40 & 2,872906 & Tercemar ringan \\
20 & 0,489871 & Memenuhi Baku Mutu & 41 & 2,464229 & Tercemar ringan \\
21 & 0,381449 & Memenuhi Baku Mutu & 42 & 1,686999 & Tercemar ringan \\
\hline
\end{tabular}


Indeks pencemaran yang didapat pada indikator fisik yaitu memenuhi baku mutu, tercemar ringan, dan tercemar sedang. Kelas indeks pencemaran $0 \leq P I \leq 1,0$ yang termasuk memenuhi baku mutu terdiri dari 8 titik lokasi. Kelas indeks pencemaran $1,0<P I \leq 5,0$ yang termasuk tercemar ringan terdiri dari 24 titik lokasi. Kelas indeks pencemaran $5,0<P I \leq 10$ yang termasuk tercemar sedang terdiri dari 10 titik lokasi. Dapat dilihat pada Gambar 1.

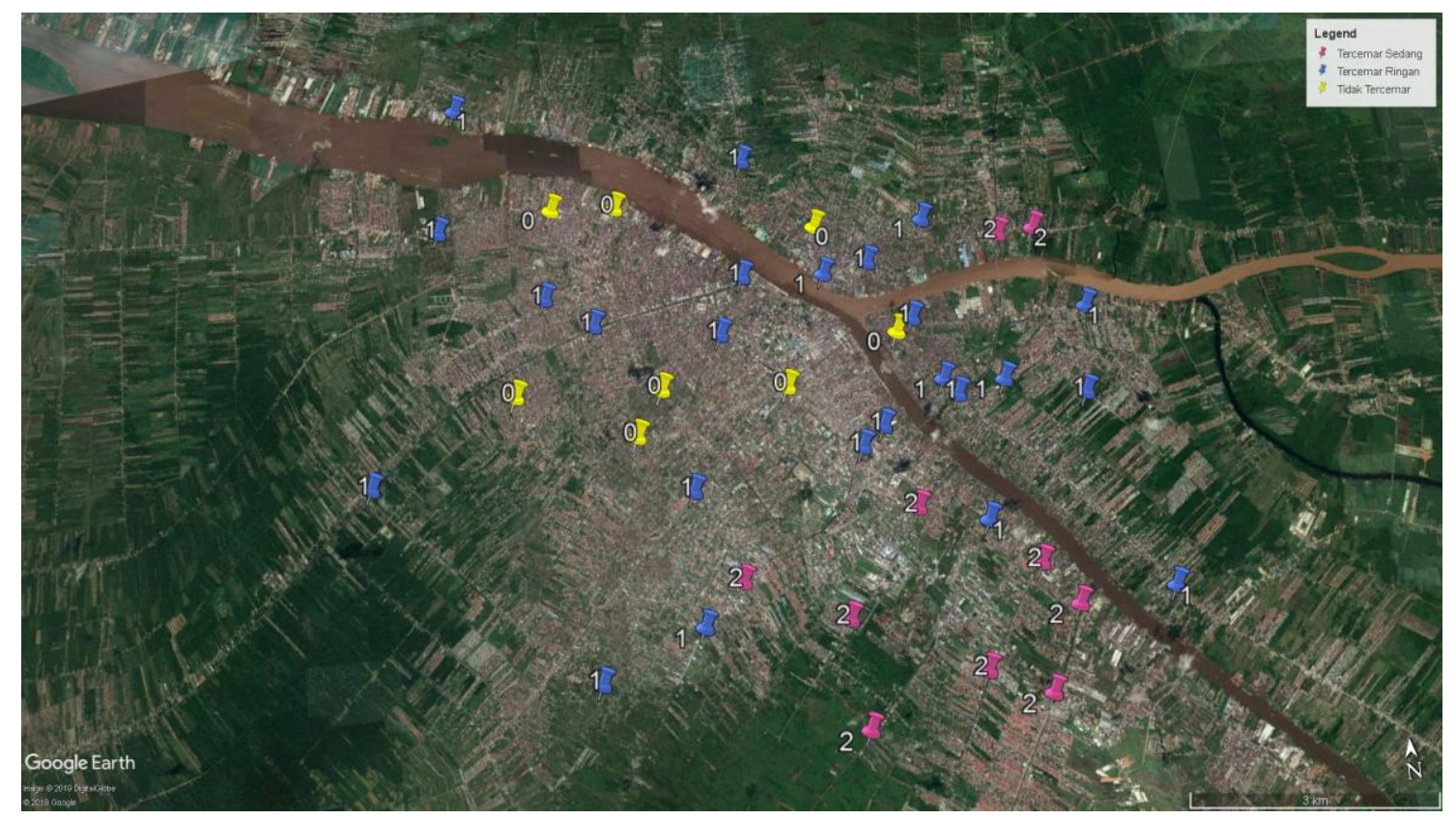

Gambar 1. Peta Titik Lokasi Sampel Indikator Fisik

Tabel 4 Nilai Indeks Pencemaran Indikator Kimia Sampel Pertama

\begin{tabular}{lcccc}
\hline Variabel & $C_{i j}$ & $L_{i j}$ & $\left(C_{i j} / L_{i j}\right)$ & $\left(C_{i j} / L_{i j}\right)$ baru \\
\hline $\mathrm{pH}$ & 5,08 & $6,5-8,5$ & 2,42 & 2,42 \\
Besi & 1,72 & 1 & 1,72 & 2,17764 \\
Fluorida & 0,38 & 1,5 & 0,25333 & 0,25333 \\
Kesadahan & 38 & 500 & 0,076 & 0,076 \\
Nitrat & 1,4 & 10 & 0,14 & 0,14 \\
Nitrit & 0 & 1 & 0 & 0 \\
Detergen & 0,001 & 0,05 & 0,02 & 0,02 \\
\hline$R_{j}{ }^{2}$ & & & & 0,52811 \\
$M_{j}^{2}$ & & & & 5,8564 \\
$P I_{j}$ & & & & 1,78669 \\
\hline
\end{tabular}

Pada Tabel 4 didapat hasil indeks pencemaran sebesar 1,78669 menurut tabel kriteria indeks pencemaran sampel pertama termasuk dalam kategori tercemar ringan. Hasil perhitungan seluruh sampel indikator kimia dapat dilihat pada Tabel 5 
Tabel 5 Nilai Indeks Pencemaran Indikator Kimia

\begin{tabular}{cccccc}
\hline Sampel & $P_{j}$ & $\begin{array}{c}\text { Kriteria Indeks } \\
\text { Pencemaran }\end{array}$ & Sampel & $P I_{j}$ & $\begin{array}{c}\text { Kriteria Indeks } \\
\text { Pencemaran }\end{array}$ \\
\hline 1 & 1,786688 & Tercemar ringan & 22 & 0,631958 & Memenuhi Baku Mutu \\
2 & 1,767792 & Tercemar ringan & 23 & 0,750934 & Memenuhi Baku Mutu \\
3 & 2,395329 & Tercemar Ringan & 24 & 2,805444 & Tercemar Ringan \\
4 & 1,303215 & Tercemar Ringan & 25 & 2,008437 & Tercemar Ringan \\
5 & 1,514015 & Tercemar Ringan & 26 & 1,926083 & Tercemar Ringan \\
6 & 0,385907 & Memenuhi Baku Mutu & 27 & 2,407335 & Tercemar Ringan \\
7 & 1,400871 & Tercemar Ringan & 28 & 2,069797 & Tercemar Ringan \\
8 & 1,449119 & Tercemar Ringan & 29 & 2,080839 & Tercemar Ringan \\
9 & 0,725516 & Memenuhi Baku Mutu & 30 & 2,617623 & Tercemar Ringan \\
10 & 0,437054 & Memenuhi Baku Mutu & 31 & 2,574267 & Tercemar Ringan \\
11 & 2,197224 & Tercemar Ringan & 32 & 2,328835 & Tercemar Ringan \\
12 & 1,905120 & Tercemar Ringan & 33 & 0,595594 & Memenuhi Baku Mutu \\
13 & 0,805405 & Memenuhi Baku Mutu & 34 & 2,264723 & Tercemar Ringan \\
14 & 1,373411 & Tercemar Ringan & 35 & 2,100950 & Tercemar Ringan \\
15 & 0,958799 & Memenuhi Baku Mutu & 36 & 2,517070 & Tercemar Ringan \\
16 & 1,321450 & Tercemar Ringan & 37 & 2,210400 & Tercemar Ringan \\
17 & 0,612488 & Memenuhi Baku Mutu & 38 & 3,571186 & Tercemar Ringan \\
18 & 0,491048 & Memenuhi Baku Mutu & 39 & 3,548021 & Tercemar Ringan \\
19 & 1,035280 & Tercemar Ringan & 40 & 2,815619 & Tercemar Ringan \\
20 & 0,197823 & Memenuhi Baku Mutu & 41 & 2,009002 & Tercemar Ringan \\
21 & 0,414510 & Memenuhi Baku Mutu & 42 & 1,909308 & Tercemar Ringan \\
\hline
\end{tabular}

Indeks pencemaran yang didapat pada indikator kimia yaitu memenuhi baku mutu dan tercemar ringan. Kelas indeks pencemaran $0 \leq P I \leq 1,0$ yang termasuk memenuhi baku mutu terdiri dari 12 titik lokasi. Kelas indeks pencemaran $1,0<P I \leq 5,0$ yang termasuk tercemar ringan terdiri dari 30 titik lokasi. Dapat dilihat pada Gambar 2.

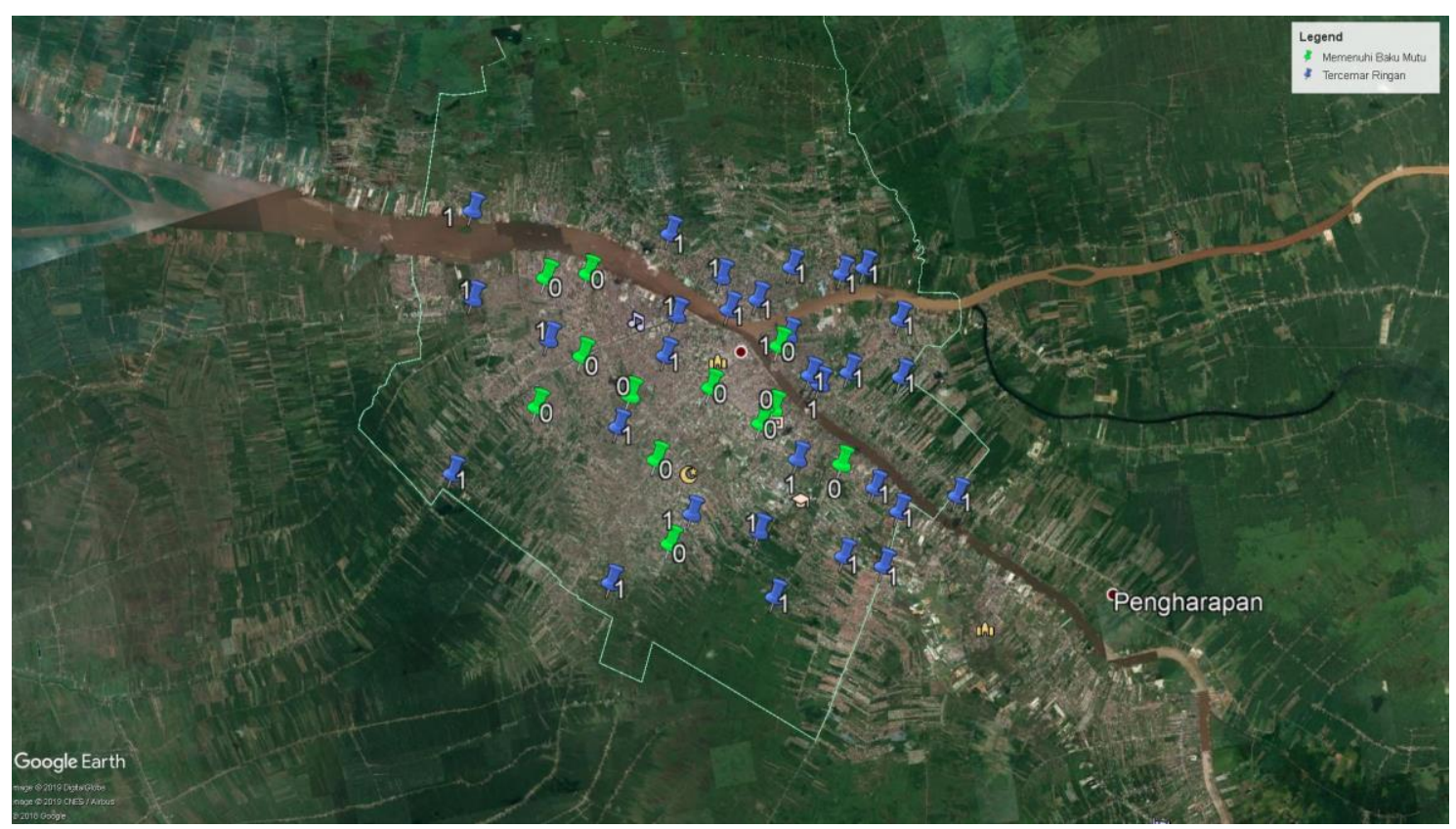

Gambar 2. Peta Titik Lokasi Sampel Indikator Kimia 


\section{KESIMPULAN}

Indeks pencemaran indikator fisik terdiri dari tiga kelas yaitu, 8 titik lokasi memenuhi baku mutu, 24 titik lokasi tercemar ringan, dan 10 titik lokasi tercemar sedang. Indeks pencemaran indikator kimia terdiri dari dua kelas yaitu, 12 titik lokasi memenuhi baku mutu dan 30 titik lokasi tercemar ringan.

\section{UCAPAN TERIMA KASIH}

Ucapan terima kasih disampaikan kepada Kementerian Riset, Teknologi, dan Pendidikan Tinggi atas dukungan dana bagi penelitian ini yang diberikan kepada Dadan Kusnandar, Naomi Nessyana Debataraja, dan Rossi Widya Nusantara. Makalah ini merupakan bagian dari hasil penelitian tersebut. Analisis diskriminan terhadap data dalam penelitian ini dipublikasikan dalam jurnal Applied Mathematical Sciences (Kusnandar, Debataraja dan Dewi (inpress)).

\section{DAFTAR PUSTAKA}

[1]. Republik Indonesia. Peraturan Menteri Kesehatan Republik Indonesia Nomor 32 Tahun 2017 Tentang Standar Baku Mutu Kesehatan Lingkungan dan Persyaratan Kesehatan Air Untuk Keperluan Higiene Sanitasi, Kolam Renang, Solus per Aqua dan Pemandian Umum. Sekretariat Negara. Jakarta; 2017.

[2]. Debataraja, N. N., Kusnandar, D., dan Nusantara, R. W. Identifikasi Lokasi Sebaran Pencemaran Air di Kawasan Permukiman Kota Pontianak. Jurnal Matematika, Statistika, dan Komputasi. 2018; 15(1); 37-41.

[3]. Republik Indonesia. Peraturan Menteri Lingkungan Hidup Nomor 115 Tahun 2003 Tentang Pedoman Penentuan Status Mutu Air. Jakarta; 2003.

[4]. Andara, D. R., Haeruddin, dan Suryoanto, A. Kandungan Total Padatan Tersuspensi, Biochemical Oxygen Demand dan Chemical Oxygen Demand serta Indeks Pencemaran Sungai Klampisan di Kawasan Industri Candi, Semarang. Diponegoro Journal of Maquares. 3(3): 177$187 ; 2014$.

PUTERI RATNA DEWI

DADAN KUSNANDAR

NAOMI NESSYANA DEBATARAJA
: Jurusan Matematika FMIPA UNTAN, Pontianak puteriratnadewi@gmail.com : Jurusan Matematika FMIPA UNTAN, Pontianak dkusnand@untan.ac.id

: Jurusan Matematika FMIPA UNTAN, Pontianak naominessyana@math.untan.ac.id 